\title{
Functional Requirements of the Yellow Fever Virus Capsid Protein ${ }^{\nabla}$
}

\author{
Chinmay G. Patkar, $\dagger$ Christopher T. Jones, $\uparrow \ddagger$ Yu-hsuan Chang, Ranjit Warrier, and Richard J. Kuhn* \\ Department of Biological Sciences, Purdue University, 915 W. State Street, West Lafayette, Indiana 47907-2054
}

Received 27 September 2006/Accepted 23 March 2007

\begin{abstract}
Although it is known that the flavivirus capsid protein is essential for genome packaging and formation of infectious particles, the minimal requirements of the dimeric capsid protein for virus assembly/disassembly have not been characterized. By use of a trans-packaging system that involved packaging a yellow fever virus (YFV) replicon into pseudo-infectious particles by supplying the YFV structural proteins using a Sindbis virus helper construct, the functional elements within the YFV capsid protein (YFC) were characterized. Various Nand C-terminal truncations, internal deletions, and point mutations of YFC were analyzed for their ability to package the YFV replicon. Consistent with previous reports on the tick-borne encephalitis virus capsid protein, YFC demonstrates remarkable functional flexibility. Nearly 40 residues of YFC could be removed from the $\mathbf{N}$ terminus while the ability to package replicon RNA was retained. Additionally, YFC containing a deletion of approximately 27 residues of the $\mathrm{C}$ terminus, including a complete deletion of $\mathrm{C}$-terminal helix 4 , was functional. Internal deletions encompassing the internal hydrophobic sequence in YFC were, in general, tolerated to a lesser extent. Site-directed mutagenesis of helix 4 residues predicted to be involved in intermonomeric interactions were also analyzed, and although single mutations did not affect packaging, a YFC with the double mutation of leucine 81 and valine 88 was nonfunctional. The effects of mutations in YFC on the viability of YFV infection were also analyzed, and these results were similar to those obtained using the replicon packaging system, thus underscoring the flexibility of YFC with respect to the requirements for its functioning.
\end{abstract}

Flaviviruses are small, spherical, enveloped viruses with a positive-sense RNA genome. The flavivirus genome (approximately 11,000 nucleotides) encodes three structural proteins and seven nonstructural proteins from a single open reading frame (25). The nonstructural proteins are responsible for various enzymatic activities, including those of RNA-dependent RNA polymerase, helicase, and protease, that are essential for the process of genome replication and as a result have been the primary focus of antiviral drug development in recent years. The structural proteins, along with the host-derived lipid bilayer and a single copy of the RNA genome, assemble to form the flavivirus virion. The flavivirus virion is $\sim 50 \mathrm{~nm}$ in diameter with a relatively smooth outer surface that is constructed from 180 copies of both the major envelope (E) protein and the small membrane $(\mathrm{M})$ protein. The $\mathrm{E}$ and $\mathrm{M}$ proteins are anchored to the underlying viral membrane via C-terminal transmembrane domains. At the center of the virion resides the nucleocapsid core, which is composed of the capsid (C) protein in complex with the viral genome $(22,32$, 41).

The $\mathrm{E}$ protein is responsible for virus binding to host cells and, following receptor-mediated endocytosis, low-pH-induced fusion of the viral and host membranes which ultimately results in release of the nucleocapsid into the cytoplasm of the infected cell $(1,8,25)$. The importance of the M protein in the virion structure is not clear, but in its immature state (prM) it

\footnotetext{
* Corresponding author. Mailing address: Department of Biological Sciences, Purdue University, 915 W. State Street, West Lafayette, IN 47907-2054. Phone: (765) 494-1164. Fax: (765) 496-1189. E-mail: kuhnr@purdue.edu.

$\uparrow$ These authors contributed equally to the study.

$\$$ Present address: Laboratory of Virology and Infectious Disease, The Rockefeller University, 1230 York Avenue, New York, NY 10021.

${ }^{\nabla}$ Published ahead of print on 4 April 2007.
}

functions to protect the E protein from premature fusion during virion morphogenesis (42). By themselves, the E and (pr)M proteins are able to assemble into noninfectious virus-like particles (VLPs). VLPs are small $T=1$ particles that are normally produced during flavivirus infectious $(11,25)$. Similar, if not identical, particles have also been produced by expression of the $\mathrm{E}$ and $\mathrm{prM}$ proteins in several heterologous expression systems $(3,12,20,21,34)$. In addition, the production of larger VLPs, which are likely to be structurally equivalent to virus particles, yet lacking nucleocapsids, have been reported, indicating that the structural determinants of enveloped virus assembly (i.e., the ability to form a closed spherical shell) can function independently of the C protein (2).

The molecular organization of the outer surfaces of the mature $(\mathrm{E}$ and $\mathrm{M})$ and immature $(\mathrm{E}$ and $\mathrm{prM})$ virions have been determined by using a combination of cryoelectron microscopy of whole virions and available atomic resolution structures of isolated E protein $(22,30,35,32,42,43)$. In contrast, the organization and molecular interactions of the $\mathrm{C}$ protein within the nucleocapsid of the virion are currently unknown. Cryoelectron microscopy reconstructions of both dengue virus type 2 (DEN2) and West Nile virus (WNV) reveal a nucleocapsid core that apparently lacks organization or has a different symmetry than the outer envelope $(22,30)$. Indeed, the nucleocapsid core lacks a distinct $\mathrm{C}$ protein shell, suggesting that the $\mathrm{C}$ protein and viral RNA assemble in a random way. Perhaps most surprisingly, the nucleocapsid lacks connectivity with the surrounding viral membrane, suggesting that few if any interactions take place between the $\mathrm{C}$ protein and the $\mathrm{E}$ and $\mathrm{M}$ proteins. However, the essential nature of the $\mathrm{C}$ protein for packaging the viral RNA into virions has been demonstrated and suggests that the $C$ protein may represent a potentially useful target for the development of novel antiviral strategies (14). The $\mathrm{C}$ protein was recently shown to be an 
A.

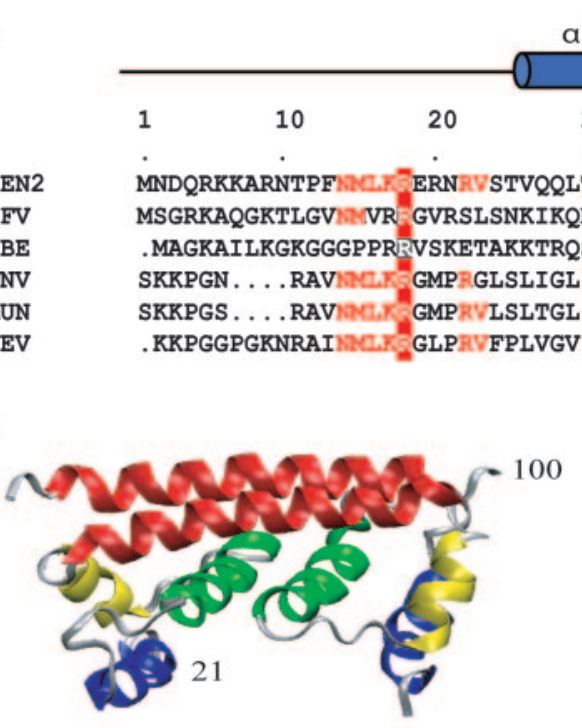

B. a1

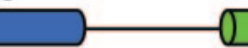

40 a2

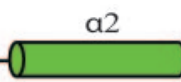

50

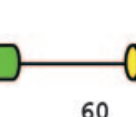

a3

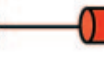

70

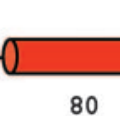

80

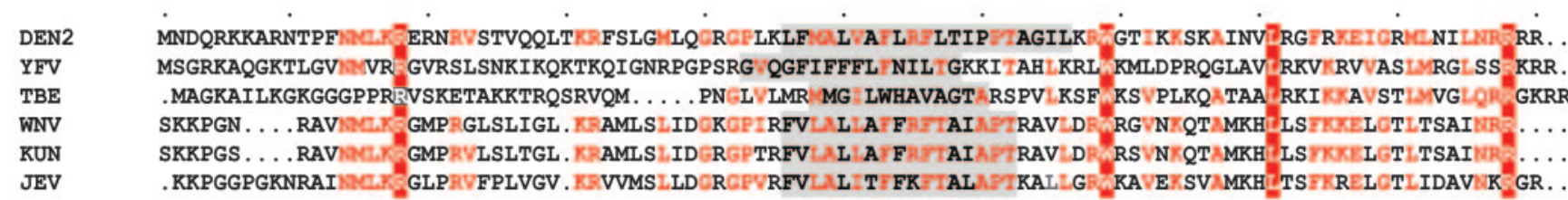

C.

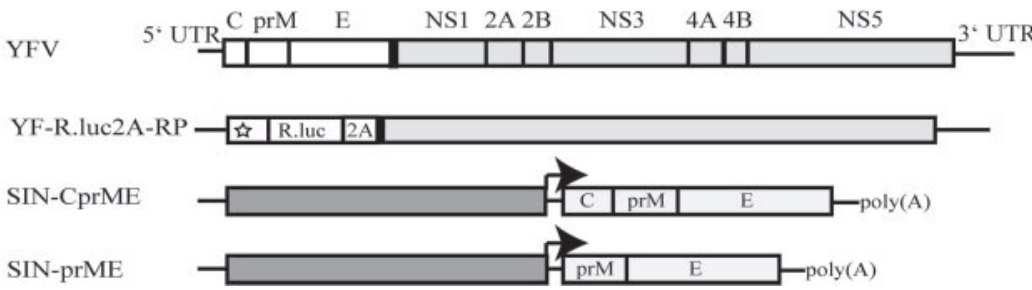

FIG. 1. (A) Multiple sequence alignment of flavivirus C proteins. Residues with high similarity ( $>50 \%)$ are shown in red, and the conserved residues are indicated by the solid red bar. The IHS is shaded in gray. The secondary structure for DENC showng helices 1 through 4 is indicated at the top. JEV, Japanese encephalitis virus. (B) Ribbon diagram of the DENC dimer, residues 21 to 100 (26). Helix $\alpha 1$ is blue, $\alpha 2$ is green, $\alpha 3$ is yellow, and $\alpha 4$ is red (image generated using Visual Molecular Dynamics [VMD]; University of Illinois, Urbana-Champaign). (C) Schematic representation of the YFV genome, with open boxes denoting regions coding for the structural (white) and nonstructural (light gray) proteins that are translated as a polyprotein. The 5'- and $3^{\prime}$-untranslated regions (UTR) are depicted as solid lines. Also shown is a schematic representation of the YFV replicon construct, YF-R.Luc2A-RP (14). A light gray box denotes the YFV nonstructural protein coding sequence. The star indicates the location of the RNA cyclization sequence within the coding sequence for the first 20 residues of the C protein, which is retained in the replicon. The black box indicates the NS1 signal sequence. R.luc, Renilla luciferase; 2A, a 17-amino-acid residue autoproteolytic peptide from foot-andmouth disease virus. Also shown is a schematic representation of the SIN replicon constructs that were used to express YFV structural proteins, SIN-CprME and SIN-prME. The coding sequence for the SIN nonstructural proteins, nsP1-nsP4, is denoted by a dark gray box. The YFV structural proteins (white box) are expressed from the SIN subgenomic promoter (black arrow). Lines indicate 5'-and 3'-UTRs, and the poly A tail is shown.

effective target for generating highly attenuated vaccine strains of tick-borne encephalitis virus (TBEV) $(18,28)$.

The $\mathrm{C}$ protein is an $\sim 12-\mathrm{kDa}$, highly basic protein, with the lowest conservation of the flavivirus proteins. RNA binding studies have implicated the first 32 and last 26 residues of the Kunjin virus (KUN) C protein (KUNC) in binding of the viral RNA (15). The $\sim 20$-residue hydrophobic $C$ terminus of the precursor $\mathrm{C}$ protein anchors the $\mathrm{C}$ protein to the cytoplasmic side of endoplasmic reticulum (ER) membranes and functions as a signal sequence for translocation of the prM protein into the lumen of the ER. The $\mathrm{C}$ protein found in virions lacks the $\mathrm{C}$-terminal signal sequence and is the result of a proteolytic cleavage by the viral protease NS2B-NS3 $(4,39,40)$. The mature form of the $\mathrm{C}$ protein remains associated with intracellular membranes via an internal hydrophobic sequence (IHS) that is conserved in all flavivirus C proteins (29).

The solution structure of the DEN C protein (DENC) expressed in Escherichia coli was previously determined by nuclear magnetic resonance techniques and is a dimer in solution with each subunit composed of four alpha helices ( $\alpha 1$ to $\alpha 4$ ) (Fig. 1B) (26). The N-terminal $\sim 20$ residues of the DENC are unstructured in solution. The first three helices $(\alpha 1$ to $\alpha 3)$ form a right-handed bundle that comprises the monomer core of the DENC protein, and $\alpha 4$, the longest helix, extends away from the monomer core. The $\alpha 4$ from each monomer shows a high density of basic residues on the solvent-accessible surface and is proposed to interact with the viral RNA. On the opposite face the surface contributed by $\alpha 2$ and $\alpha 1$ is largely uncharged.
On that side of the DENC dimer, the IHS from each monomer associate to form a rather extensive dimerization interface spanning residues 46 to 66 that creates a solvent-accessible nonpolar patch, and it has been suggested that this nonpolar face is responsible for the membrane association of the $\mathrm{C}$ protein. However, the importance of this property of the $\mathrm{C}$ protein is not clear, since large deletions spanning much of the IHS of the TBEV C protein (TBEC), which have only moderate effects on virus viability, have been described (18). The crystal structure of the KUNC (KUN is closely related to WNV, differing at only four residues in the $\mathrm{C}$ protein) has recently been reported and exhibits a fold that is very similar overall to that of DENC, with the exception of the relative orientation of $\alpha 1$ (10).

Despite the low sequence identity of the flavivirus $\mathrm{C}$ proteins, certain features are well conserved in all flaviviruses (Fig. 1A). Firstly, the flavivirus $C$ protein is highly basic, reflecting its function in the binding and encapsidation of the viral RNA. Secondly, the C protein possesses an IHS, the length of which varies from 14 to 22 hydrophobic residues among the different flavivirus species. While the IHS was previously shown to be necessary and sufficient to mediate membrane association of the $\mathrm{C}$ protein, the importance of this association has not been established (29). The oligomeric state of the $\mathrm{C}$ protein is also apparently conserved, since in the cases of DEN2, WNV, KUN, yellow fever virus (YFV), and TBEV, the C protein is dimeric in solution $(10,13,17,26)$. The relevance of the dimeric state of the $\mathrm{C}$ protein during virion morphogenesis has 
not been clearly demonstrated but is thought to play a functional role. Nucleocapsid core-like particles (CLPs) have been assembled from purified dimeric TBEC when combined with nucleic acid in vitro, suggesting that the dimeric form of the $\mathrm{C}$ protein might function as one of the building blocks of virion assembly (17).

Previously we described the construction of a noninfectious YFV replicon (YF-R.luc2A-RP) that encodes the Renilla luciferase reporter gene (Fig. 1C) (14). Moreover, it was shown that a Sindbis virus (SIN)-based replicon expressing the YFV structural proteins in trans (SIN-CprME) could be used to package YF-R.luc2A-RP replicon RNA into pseudo-infectious virus particles (PIPs) (Fig. 1C). Importantly, it was also demonstrated that the $\mathrm{C}$ protein was essential for the production of PIPs as SIN-prME; a construct lacking the C protein was incapable of packaging replicon RNA. Therefore, deletion analysis of the $\mathrm{C}$ protein in the context of the trans-packaging system could be used to define the functional regions of the $\mathrm{C}$ protein. Here we report the use of this system to define the minimal functional sequences of the flavivirus $\mathrm{C}$ protein. Consistent with previous reports on TBEC, the YFV C protein (YFC) demonstrates remarkable functional flexibility. Nearly $40 \%$ of the $\mathrm{C}$ protein from the $\mathrm{N}$ terminus could be removed, while the ability to package replicon RNA was retained. In addition, the $\mathrm{C}$ protein function was tolerant of deletion of approximately $30 \%$ of the $\mathrm{C}$ terminus, including a complete deletion of $\alpha 4$. Internal deletions encompassing the IHS were, in general, tolerated to a lesser extent. The effects of mutations in the $\mathrm{C}$ protein on the viability of YFV infection were also tested, and these results were in accordance with those obtained using the replicon packaging system.

\section{MATERIALS AND METHODS}

Cell culture and virus stocks. BHK-15 cells obtained from the American Type Culture Collection were maintained in minimal essential medium (MEM; Life Technologies) containing $10 \%$ fetal bovine serum (FBS). Cells were grown at $37^{\circ} \mathrm{C}$ in the presence of $5 \% \mathrm{CO}_{2}$. YFV stocks were generated by standard procedures from pYF23, a plasmid derived from pACNR/FLYF (a full-length cDNA clone of YFV 17D kindly provided by C. M. Rice). For plaque assays, 10 -fold serial dilutions of culture supernatant were made in phosphate-buffered saline (PBS) containing 1\% FBS. Cells at a density of 80 to $90 \%$ were inoculated with the serial dilutions. After being infected at $37^{\circ} \mathrm{C}$ for $1 \mathrm{~h}$, monolayers were overlaid with agarose, incubated for 3 days, and stained with 5\% Neutral Red. For analysis of virus growth, BHK cells were transfected with either wild-type or mutated RNA transcripts, culture supernatants were harvested at various time points, and the virus titer was determined by a standard plaque assay.

Plasmids and cloning procedures. Replicons of YFV were derived from YF23, a full-length cDNA clone of YFV. The construction of the YF-R.luc2A-RP replicon has been described previously (14). SIN-based replicons that expressed the YFV structural proteins were constructed from pToto64, a full-length cDNA clone of SIN. The construction of the SIN-prME and SIN-CprME helper replicon constructs is also described in reference 14. All mutations within the coding sequence for the $\mathrm{C}$ protein were engineered in the SIN-CprME replicon or the pYF23 full-length plasmid constructs by using standard PCR mutagenesis techniques.

RNA transcription and transfection. RNA transcripts of YFV, both full-length and replicon constructs, and SIN replicons were generated by in vitro transcription using SP6 RNA polymerase (Amersham Biosciences) from DNA templates that had been linearized by digestion with XhoI and SacI restriction enzymes, respectively, and that were subsequently purified using GFX columns (Amersham Biosciences). For electroporation of BHK-15 cells, 90\% subconfluent monolayers of cells grown in T-75 culture flasks $\left(\sim 1 \times 10^{6}\right.$ cells $)$ were harvested by trypsinization and washed twice with PBS before finally being resuspended in $400 \mu \mathrm{l}$ of PBS. The resulting cells were combined with $\sim 10 \mu \mathrm{g}$ of in vitrotranscribed RNA, placed in a 2-mm-diameter Gene Pulser cuvette (Bio-Rad), and electroporated (two pulses at settings of $1.5 \mathrm{kV}, 25 \mu \mathrm{F}$, and $200 \Omega$ ) using a GenePulser II apparatus (Bio-Rad). Following $5 \mathrm{~min}$ of recovery at room temperature, the cells were resuspended in MEM supplemented with $10 \%$ FBS. For transfection using Lipofectamine 2000 reagent (Invitrogen), the Lipofectamine reagent was diluted in OptiMEM (Invitrogen) according to the manufacturer's instruction and incubated at room temperature for $5 \mathrm{~min}$. Following the 5-min incubation, in vitro-transcribed RNA $(\sim 5 \mu \mathrm{g})$ in OptiMEM was then added to the diluted Lipofectamine and incubated for an additional $20 \mathrm{~min}$ at room temperature. The RNA-Lipofectamine mixture was then added directly to the BHK cells in MEM with 5\% FBS.

Generation of PIPs. BHK-15 cells were electroporated with in vitro-transcribed YF-R.luc2A-RP replicon RNA, and resuspended cells were placed in a 24-well plate and incubated at $37^{\circ} \mathrm{C}$ for 12 to $15 \mathrm{~h}$. The cells were thoroughly washed with PBS to get rid of unincorporated replicon RNA. SIN replicon transcripts, containing either wild-type full-length or mutated $\mathrm{C}$ protein, were transfected with Lipofectamine 2000 reagent (Invitrogen) into the previously electroporated cells to initiate production of PIPs. Cell supernatants from the cotransfected cells were harvested at $12 \mathrm{~h}$ following the second transfection, and $100 \mu \mathrm{l}$ of supernatant was used to infect naïve BHK cells. Cell extracts were taken from these cells at $24 \mathrm{~h}$ postinfection, and luciferase assays were performed.

Luciferase assays. To determine the Renilla luciferase activity, cells were washed with PBS and lysed using Renilla lysis buffer, and lysates were stored at $-80^{\circ} \mathrm{C}$. The extracts were thawed at room temperature and immediately used in the assay. Luciferase activity was initiated by addition of $10 \mu \mathrm{l}$ of cytoplasmic extracts to $50 \mu \mathrm{l}$ of Renilla luciferase substrate (Promega). The luciferase activity was detected using a Lumat luminometer system (Berthold) and measured in raw light units (RLU).

Rate of zonal-gradient centrifugation. Culture supernatants $(1.5 \mathrm{ml})$ containing PIPs were loaded on to continuous 5 to $40 \%$ OptiPrep gradients in Tris$\mathrm{NaCl}$-EDTA buffer. Centrifugation was performed using a SW41 rotor (Beckman) at $38,000 \mathrm{rpm}$ for $7 \mathrm{~h}$ at $4^{\circ} \mathrm{C}$. Gradients were fractionated manually into $500-\mu$ l fractions. BHK-15 cells were infected with $100 \mu \mathrm{l}$ of each fraction. The cells were overlaid with an appropriate volume of MEM containing 5\% FBS, and a luciferase assay was performed $24 \mathrm{~h}$ postinfection.

Thermal stability. One hundred microliters of PIPs was incubated at $49^{\circ} \mathrm{C}$ for 10, 20, 30, 40, or $50 \mathrm{~min}$. After each time point, the PIPs were incubated at $4^{\circ} \mathrm{C}$. BHK-15 cells were then infected with all $100 \mu$ l of PIPs. The cells were overlaid with an appropriate volume of MEM containing 5\% FBS, and a luciferase assay was performed $24 \mathrm{~h}$ postinfection.

\section{RESULTS}

Previously, the procedure developed for trans packaging in BHK-15 cells relied on sequential electroporations with first the YF-R.luc2A-RP RNA and then the SIN-CprME RNA, and an optimal time interval of $24 \mathrm{~h}$ was used between electroporations. However, during preliminary experiments it became clear that a modification of the previously established procedure was necessary to facilitate screening of large numbers of $\mathrm{C}$ protein deletion mutants. Here, after electroporation of the YF-R.luc2A-RP RNA, BHK-15 cells were dispensed into a 24-well plate, and $12 \mathrm{~h}$ postelectroporation, the SINCprME RNA was transfected into these cells using Lipofectamine 2000.

Truncations of the unstructured $\mathbf{N}$ terminus of the $\mathrm{C}$ protein. Within the coding region for the $\mathrm{N}$ terminus of the $\mathrm{C}$ protein resides a cis-acting element that mediates cyclization with a complementary sequence located in the 3 '-nontranslated region of the flavivirus genome (16). Several groups have observed that deletion of this $5^{\prime}$-cyclization sequence prevents flavivirus replication (7). In YFV, a 21-nucleotide region spanning amino acid residues 9 to 15 of the $\mathrm{C}$ protein coding sequence was found to be essential for robust replication (7). However, the function of the amino acid residues encoded by the $5^{\prime}$-cyclization sequence has not been addressed. The $\mathrm{N}$ terminus of the $\mathrm{C}$ protein is enriched in basic residues, which 
A.
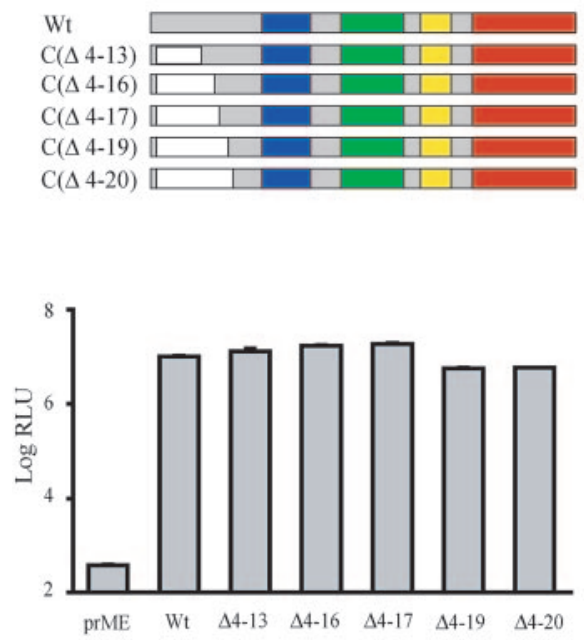

C.
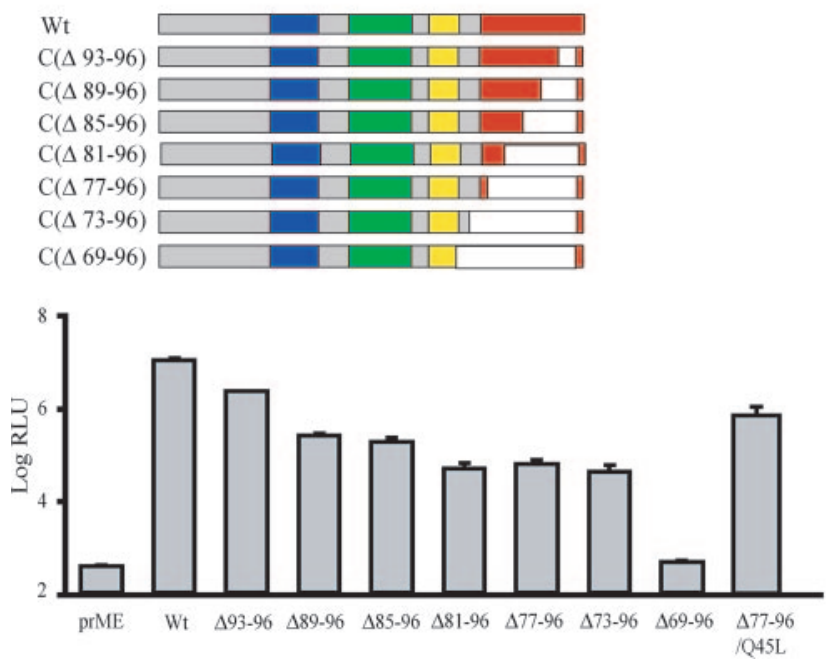

B.
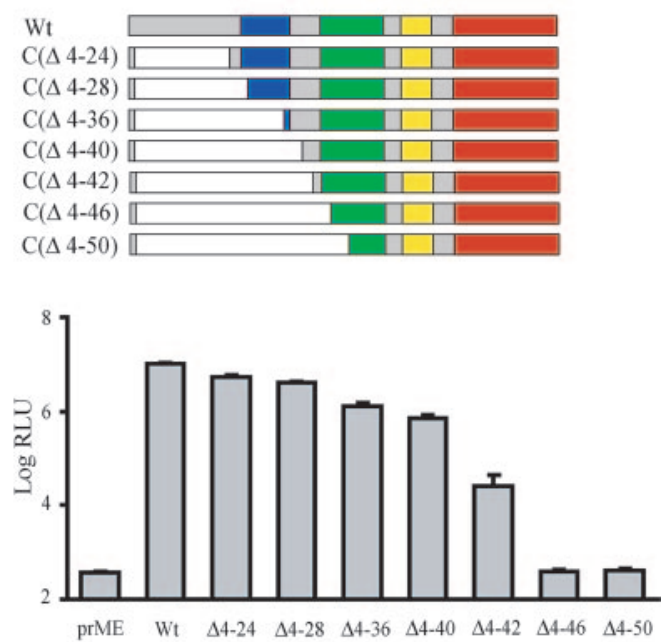

D.
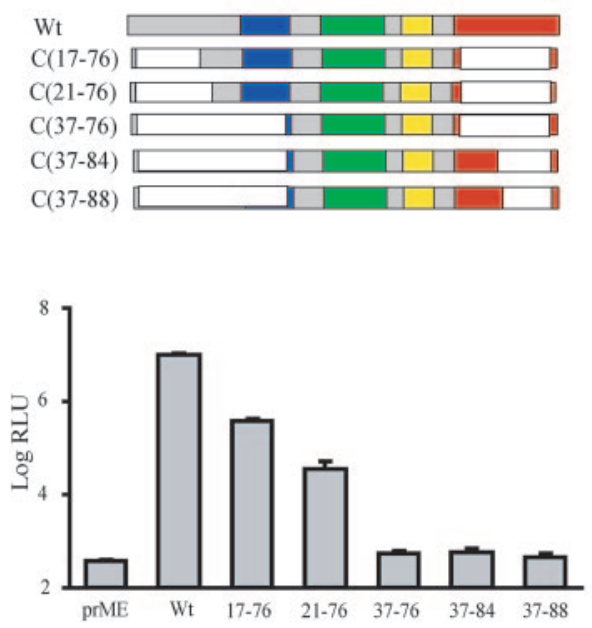

FIG. 2. Packaging of YF-R.luc2A-RP using truncated YFC. A schematic diagram of mutated YFC is shown, with white boxes indicating deleted residues. The helices are colored as described in the legend to Fig. 1. Graphs indicate log values of Renilla luciferase activity (Log RLU) in BHK-15 cells infected with PIPs at $24 \mathrm{~h}$ postinfection. PIPs were generated by electroporation of BHK cells with the YF-R.luc2A-RP replicon followed by transfection of full-length (Wt) or mutated SIN-CprME or SIN-prME (prME) replicon RNAs (see Materials and Methods). (A) Activity of PIPs produced using YFC containing truncations within the N-terminal unstructured region (first 20 residues). (B) Activity of PIPs produced using YFC containing truncations of the N-terminal regions (including $\alpha 1$ and $\alpha 2$ ). (C) Activity of PIPs produced using YFC containing truncations within the C-terminal domain (including $\alpha 4)$. The activity of PIPs produced using the $\mathrm{C}(\Delta 77-96)$ construct containing the Q45L revertant, labeled as $\Delta 77-96 / \mathrm{Q} 45 \mathrm{~L}$, is also shown. (D) Activity of PIPs produced using YFC containing both N- and C-terminal truncations.

would suggest that this region has a role in the binding of the viral RNA. Consistent with this notion, in vitro studies have implicated the N-terminal third of the $\mathrm{C}$ protein in RNA binding (15). Moreover, the first $\sim 20$ residues of the $\mathrm{C}$ protein are unstructured in solution, a situation analogous to that of the RNA binding regions of other positive-strand RNA virus capsid proteins. To determine the functional importance of the unstructured $\mathrm{N}$ terminus of the $\mathrm{C}$ protein, successive deletions within this region were engineered into the SIN-CprME replicon, and the resultant mutants were subsequently tested for their ability to produce PIPs in the trans-packaging system. The first three amino acids of the $\mathrm{C}$ protein were retained in all the $\mathrm{N}$-terminal truncations for efficient translation. Deletions of the $\mathrm{C}$ protein coding sequence encompassing the entire YFV
5 '-cyclization sequence had no measurable effect on $\mathrm{C}$ protein function. In fact, moderate increases in the production of PIPs were observed, with incremental $\mathrm{N}$-terminal truncations up to residue 17 (Fig. 2A). However, complete removal of the unstructured $\mathrm{N}$ terminus of the $\mathrm{C}$ protein resulted in modest (less than twofold) decreases in $\mathrm{C}$ protein activity compared to the wild type. The $\mathrm{C}$ protein mutant with residues 4 to 19 deleted $[C(\Delta 4-19)]$ exhibited the first moderate decrease in $C$ protein activity. Interestingly, Arg18 is completely conserved among flavivirus $\mathrm{C}$ proteins. However, the mutation of R18 to $\mathrm{E}$ or $\mathrm{A}$ in the context of full-length $\mathrm{C}$ protein had no measurable effect on $\mathrm{C}$ protein activity (data not shown), and thus the decrease must be due to the deletion of residues 4 to 19 and not residue R18 itself. 
Further N-terminal truncations of the $\mathbf{C}$ protein. Secondary-structure prediction indicates that YFC is composed of three alpha helices rather than the four observed in both DENC and KUNC (13). The extent and position of these helices closely resemble those of $\alpha 2$ to $\alpha 4$ in DENC, suggesting that YFC is missing the alpha helix corresponding to $\alpha 1$ in DENC. Given the apparent tolerance of YFC to deletions of at least the first 20 residues (see "Truncations of the unstructured $\mathrm{N}$ terminus of the $\mathrm{C}$ protein") and the lack of predicted secondary-structure elements within the first $\sim 40$ residues, we constructed additional $\mathrm{N}$-terminal truncations to determine the functional limits of YFC. While progressively larger $\mathrm{N}$ terminal truncations resulted in corresponding decreases in $\mathrm{C}$ protein activity as determined by the production of PIPs, removal of the first 40 residues produced a truncated $\mathrm{C}$ protein that still retained more significant activity than the wild type; a $\sim 14$-fold reduction in activity was observed for $\mathrm{C}(\Delta 4-40)$ (Fig. 2B). Removal of 39 residues from the $\mathrm{N}$ terminus [C( $\Delta 4-42)]$ resulted in low but detectable activity; however, removal of 43 residues $[C(\Delta 4-46)]$ resulted in background levels of luciferase activity, indicating that 39 residues at the $\mathrm{N}$ terminus of YFC are dispensable for $\mathrm{C}$ function but removal of an additional four residues prevents $\mathrm{C}$ activity.

C-terminal truncations of the $\mathbf{C}$ protein. The C-terminal 23 residues of DENC that comprise $\alpha 4$ extend away from the monomer core, making few intramonomer contacts. Instead, $\alpha 4$ makes extensive contacts with $\alpha 2^{\prime}, \alpha 3^{\prime}$, and $\alpha 4^{\prime}$ of the adjacent monomer (26). Thus, the C-terminal helix appears to play an important structural role in stabilizing the $\mathrm{C}$ protein dimer through multiple intermonomeric contacts. In addition, the $\mathrm{C}$ terminus, as is the case with the $\mathrm{N}$ terminus, is enriched in basic residues and has also been implicated in RNA binding (15). To examine the importance of the $\mathrm{C}$ terminus for the function of the $\mathrm{C}$ protein, a series of $\mathrm{C}$-terminal truncations were engineered, and the resultant mutants were subsequently tested for activity. To maintain the NS2B-3 cleavage site, which is present at the $\mathrm{C}$ terminus of the $\mathrm{C}$ protein before the signal sequence of prM, the last five residues that encompass the dibasic site were retained in each C-terminal truncation. Additionally, the expression levels of E protein within cells transfected with SIN-CprME transcripts containing either wild-type or mutated $\mathrm{C}$ protein were determined by immunofluorescence and Western blotting of cell extracts and were found to be essentially equivalent (data not shown). This suggested that the expression and processing of prM-E structural proteins occurred efficiently in wild-type as well as mutated $\mathrm{C}$ protein constructs, which in turn indicated that $\mathrm{C} / \mathrm{prM}$ cleavage was probably not impaired as a result of these C-terminal truncations.

The C-terminal deletion of 12 residues [C( $\Delta 85-96)]$ resulted in an $\sim 60$-fold decrease in packaging efficiency compared to that of the wild type (Fig. 2C). Although larger C-terminal deletions of up to 23 residues (spanning the entire $\alpha 4$ helix in DENC) resulted in greater decreases of luciferase activity, packaging was still detected, suggesting that much of the $\mathrm{C}$ terminus is dispensable for $\mathrm{C}$ protein function. However, the largest C-terminal deletion constructed, $C(\Delta 69-96)$, was not functional (Fig. 2C). Residue W69 is conserved among all flaviviruses and, based on DENC structure, contributes both inter- and intramonomeric contacts, thus playing a role in stabilizing both the monomer and the dimer of the $\mathrm{C}$ protein (26).

$\mathbf{N}$ - and C-terminal truncations of the $\mathbf{C}$ protein. As mentioned previously, the $\mathrm{N}$ and $\mathrm{C}$ termini are relatively enriched in basic residues and have been implicated in RNA binding. Based on the results outlined in the previous sections, both the $\mathrm{N}$ and $\mathrm{C}$ termini are dispensable for encapsidating the replicon RNA in the trans-packaging system, perhaps indicating that each terminus compensates for binding and packaging of the RNA genome in the absence of the other terminus. Coimmunoprecipitation studies with DENC identified a region of the $\mathrm{C}$ protein corresponding to residues 37 to 72 as the minimal region for homotypic interactions within the $\mathrm{C}$ protein dimer, and interestingly, in our assay $C(\Delta 4-36)$ and $C(\Delta 77-96)$ were the largest $\mathrm{N}$ - and $\mathrm{C}$-terminal truncations that retained significant activity (37). In order to investigate whether this minimal homotypic region is also the minimal functional domain of the $\mathrm{C}$ protein and to examine the contribution of each of the termini in their ability to bind RNA and package the genome, $\mathrm{N}$-terminal and C-terminal truncations were engineered simultaneously in YFC so as to create a construct that retained residues 37 to 76 [C(37-76)] (the first three and last four residues of the $\mathrm{C}$ protein were also retained, as mentioned previously). This construct was tested for activity in the transpackaging assay but was not functional. With the purpose of correcting the defect, $\mathrm{N}$ - or $\mathrm{C}$-terminal residues were incrementally added to $\mathrm{C}(37-76)$, and the resultant mutants were tested for activity. Addition of N-terminal sequences so as to retain residues 21 to $77[\mathrm{C}(21-77)]$ restored the activity, and further addition of residues to the $\mathrm{N}$ terminus to retain residues 17 to $77[\mathrm{C}(17-77)]$ increased the packaging efficiency (Fig. 2D). Surprisingly, addition of C-terminal residues 37 to 76 to obtain a construct containing residues 37 to $84, \mathrm{C}(37-84)$, was not functional, and further addition of four residues to obtain $\mathrm{C}(37-88)$ also did not restore the packaging function (Fig. 2D). Based on the above data, the $\mathrm{N}$ terminus of the $\mathrm{C}$ protein appears to contribute more than the $\mathrm{C}$ terminus for RNA binding and packaging functions. An alternative explanation for this result is that the truncated protein is poorly folded and might not form a dimer. The addition of N-terminal sequences may more efficiently restore folding and dimerization than sequences added to the $\mathrm{C}$ terminus of the protein.

Internal deletions of the $\mathbf{C}$ protein. Recently, Kofler et al. demonstrated the functional flexibility of the $\mathrm{C}$ protein through the analysis of several internal deletion mutations within TBEC in the context of infectious TBEV (18). We engineered a similar set of internal deletions to probe the functional importance of this region in YFC. $C(\Delta 26-36)$ and $\mathrm{C}(\Delta 26-42)$ had only modest effects on $\mathrm{C}$ protein function, consistent with the tolerance of TBEC for similar deletions [see the discussions of $C(\Delta 28-35)$ and $C(\Delta 28-43)$, respectively, in reference 18] (Fig. 3). Moreover, these results were consistent with the tolerance of the $\mathrm{C}$ protein for large $\mathrm{N}$-terminal truncations (see above). An even larger internal deletion was then introduced into the $\mathrm{C}$ protein $[\mathrm{C}(\Delta 26-56)]$ and tested for activity. In contrast to the smaller internal deletions $\mathrm{C}(\Delta 26-36)$ and $C(\Delta 26-42)$, the largest deletion $[C(\Delta 26-56)]$, which removed almost the entire IHS, demonstrated no PIP activity and was consistent with the results obtained for TBEC (Fig. 3).

Kofler et al. have reported the viability of TBEV harboring 

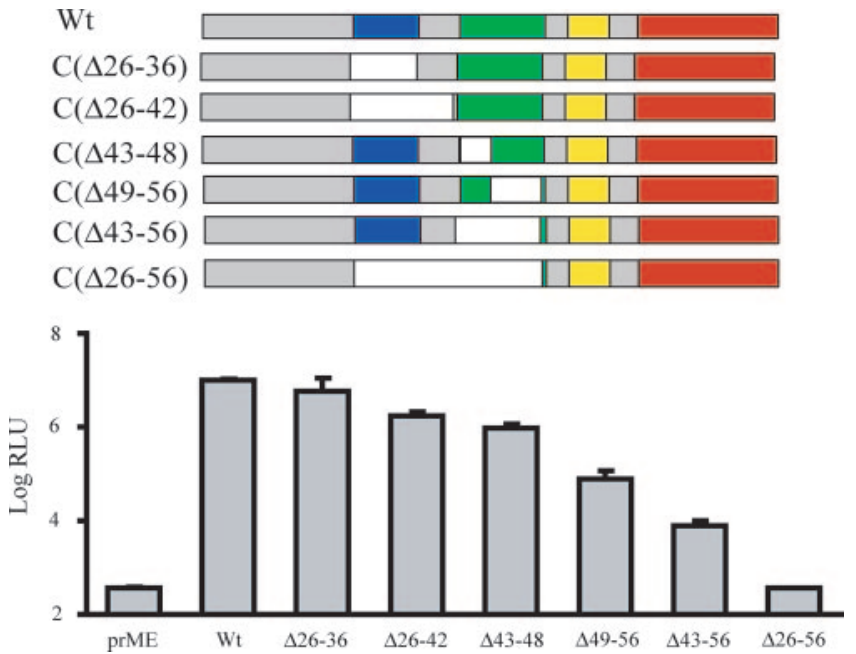

FIG. 3. Packaging of YF-R.luc2A-RP using YFC harboring internal deletions. A schematic diagram of mutated YFC is shown, with white boxes indicating deleted residues. The helices are colored as described in the legend to Fig. 1. The graph indicates log values of Renilla luciferase activity (Log RLU) in BHK-15 cells infected with PIPs at $24 \mathrm{~h}$ postinfection. PIPs were generated by electroporation of BHK cells with YF-R.Luc2A-RP replicon followed by transfection of full-length (Wt) or mutated SIN-CprME or SIN-prME (prME) replicon RNAs (see Materials and Methods). The activity of PIPs produced using YFC containing either a deletion of $\alpha 1[C(\Delta 26-36)]$, a deletion of $\alpha 1$ and the loop between $\alpha 1$ and $\alpha 2$ [C( $\Delta 26-42)]$, smaller deletions within $\alpha 2[C(\Delta 43-48)$ and $C(\Delta 49-56)]$, a deletion of the entire $\alpha 2$ $[\mathrm{C}(\Delta 43-56)]$, or a deletion of entire $\alpha 1$ and $\alpha 2[\mathrm{C}(\Delta 26-56)]$ is shown. a similar large internal deletion within the TBEC. However, without exception, the viability of the recovered virus was dependent on the emergence of certain second site mutations (19). Viruses with two types of second site mutation that restored viability, including in-frame duplication of $\mathrm{C}$ protein sequences and point mutations, were recovered. Many of the point mutations occurred within the $\mathrm{C}$ terminus (corresponding to the $\alpha 4$ in DENC). One such point mutation (K79I) was independently isolated as a second site mutation for two different internal deletion mutations. Based on sequence alignments of flavivirus $\mathrm{C}$ proteins and the DENC structure, K79 corresponds to residue R85 (K85 in YFV) (Fig. 1A). Examination of a helical wheel plot for residues in this region of the $\mathrm{C}$ protein indicates that position 85 corresponds to the $a$ position within the heptad repeat of hydrophobic residues that line the $\alpha 4-\alpha 4^{\prime}$ dimer interface (Fig. 4A). One interpretation of the results is that the second site mutation K79I stabilizes the $\alpha 4-\alpha 4^{\prime}$ interface and, therefore, the TBEC dimer. To examine this premise further, we tested the ability of the YFV substitution K85L to recover the activity of the $C(\Delta 26-56)$ deletion mutation. However, introduction of the K85L mutation into $C(\Delta 26-56)$ did not restore $C$ protein activity (data not shown).

Analysis of N-terminal truncations and the internal deletions, as mentioned above, illustrates that $\mathrm{C}$ proteins with deletions extending beyond residue 42 were nonfunctional. To examine the role of residues 43 to 56 (corresponding to $\alpha 2$ in DENC), which also encompass the IHS, smaller deletions within that region $[C(\Delta 43-48)$ and $C(\Delta 49-56)]$ and of the entire
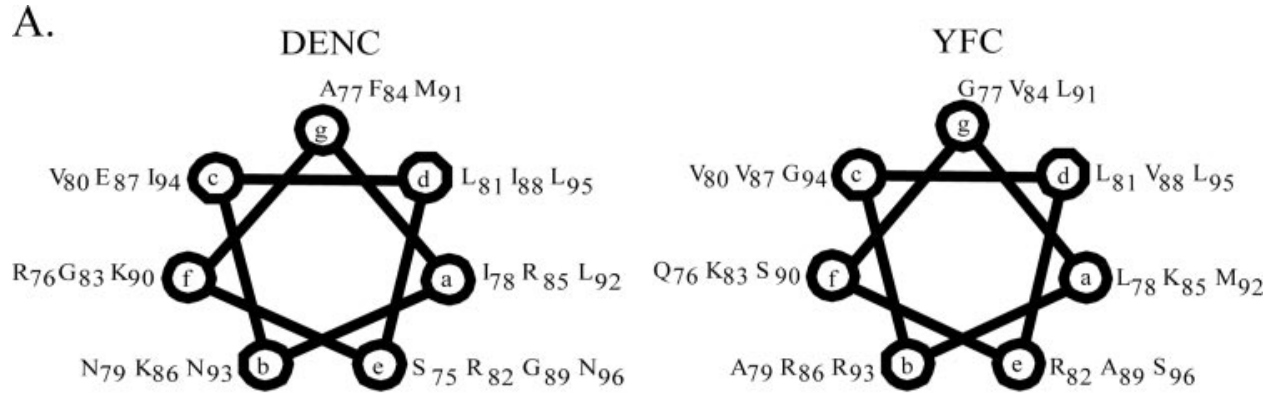

B.

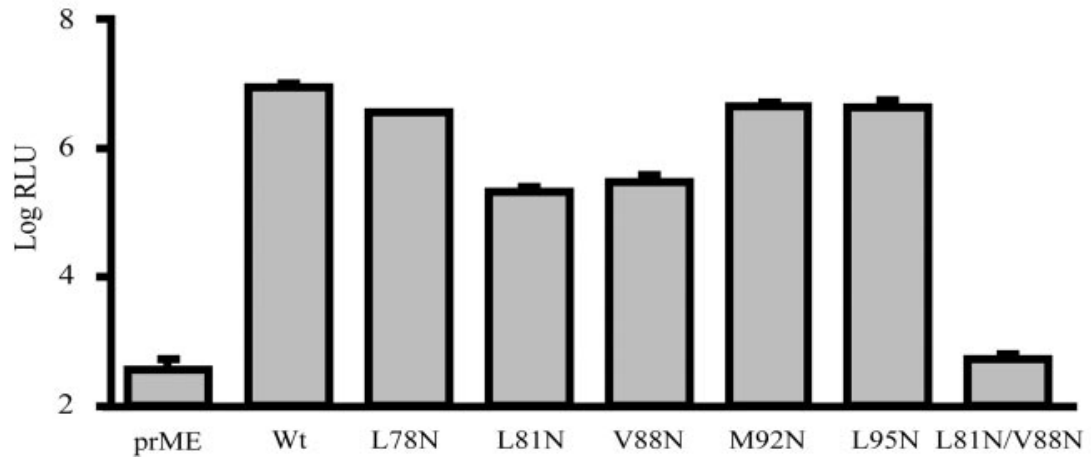

FIG. 4. (A) Helical wheel representations of the C-terminal helix, $\alpha 4$, of DENC and YFC. $\alpha 4$ shows characteristics of a coiled coil with hydrophobic residues at positions $a$ and $d$ of the helical wheel; however, R85 in DENC (K85 in YFC) in the $a$ position is an unlikely amino acid for coiled-coil structures. The side chains of L78, L81, V88, M92, and L95 in $\alpha 4$ of one monomer are involved in intermonomeric interactions with their counterparts in $\alpha 4$ of the other monomer. (B) Packaging of YF-R.luc2A-RP using YFC containing point mutations in $\alpha 4$. The activity of PIPs produced using YFC containing point mutations of residues L78, L81, V88, M92, or L95 that are involved in intermonomeric hydrophobic interactions is shown. Wt, wild type. 
helix [C( $(\Delta 43-56)]$ were made (Fig. 3A). The smaller deletions retained significant activity, but deletion of the entire region resulted in very little activity. This demonstrated that the IHS was important but not absolutely required for activity.

Point mutations in the $\mathbf{C}$-terminal helix of the $\mathbf{C}$ protein. As mentioned previously, the C-terminal helix $\alpha 4$ in DENC appears to play an important structural role in stabilizing the $\mathrm{C}$ protein dimer through multiple intermonomeric contacts. The $\alpha 4-\alpha 4^{\prime}$ interface is stabilized by interactions along the length of the helices and has the characteristics of a coiled-coil structure, including a slight superhelical twist of the helices and the packing of leucine and isoleucine side chains across the interface at positions $a$ and $d$ of a heptad repeat, although it has not been predicted to form a coiled coil by sequence-based prediction programs (26). Hydrophobic interactions between side chains of I78, L81, I88, L92, and L95 on one monomer and their counterparts on the adjacent monomer stabilize the $\alpha 4$ $\alpha 4^{\prime}$ dimer. Secondary-structure prediction programs indicate the presence of a helix, $\alpha 4$, in the C-terminal region of YFC, and the helix also has the propensity to form a coiled coil (Fig. 4A). However, in both DENC and YFC, residue 85, which is in the $a$ position, is a charged residue (arginine and lysine, respectively). The presence of a charged residue significantly reduces the propensity for the helix to adopt a coiled coil with its neighboring monomer. As shown above, the $\mathrm{C}$ terminus of YFC was completely dispensable for activity. We sought to investigate the role of the hydrophobic interactions in the $\mathrm{C}$-terminal helix in the context of the full-length $\mathrm{C}$ protein in activity. In the predicted structure of YFC, generated as a homology model based on the DENC structure, hydrophobic interactions occur between residues L78, L81, V88, M92, and L95 of one monomer and the corresponding residues of the adjacent monomer. Point mutations were made at these residues, and the resultant mutants were tested for activity (Fig. 4B). The single substitutions L78N, M92N, and L95N resulted in fairly small effects on $\mathrm{C}$ protein activity, but there was a reduction in luciferase activity with the L81N and V88N mutations compared to the wild type, suggesting that the decrease in activity might be a result of the destabilization of the dimer. Indeed, a double substitution of residues L81 and V88 to asparagine, L81N/V88N, was nonfunctional.

Characterization of the physical properties of PIPs: sedimentation density gradient centrifugation. In their analyses of TBEC mutants using rate zonal gradient centrifugation, Kofler et al. reported the mutants carrying larger deletions (such as deletion of residues 28 to 35 or larger internal deletions) sedimented with velocities between those of the control recombinant subviral particles and those of the wild-type virus (18). It was of interest to compare the size and density of the PIPs generated using different deletions within the $\mathrm{C}$ protein to those of the PIPs generated using wild-type $\mathrm{C}$ protein. To better define the physical forms of PIPs, they were separated on continuous OptiPrep gradients. The gradient fractions were used to infect BHK-15 cells, and the luciferase activity was measured (Fig. 5A). Wild-type and $C(\Delta 4-40)$ PIPs were found to sediment in the gradient at identical rates. PIPs generated using a deletion of $\alpha 1[C(\Delta 26-42)]$ were found to sediment similarly to wild-type PIPs. However, PIPs containing $C(\Delta 77$ 96) (deletion of the C-terminal helix $\alpha 4$ ) and $C(\Delta 43-48)$ (deletion of half of the IHS) sedimented at a slower rate than

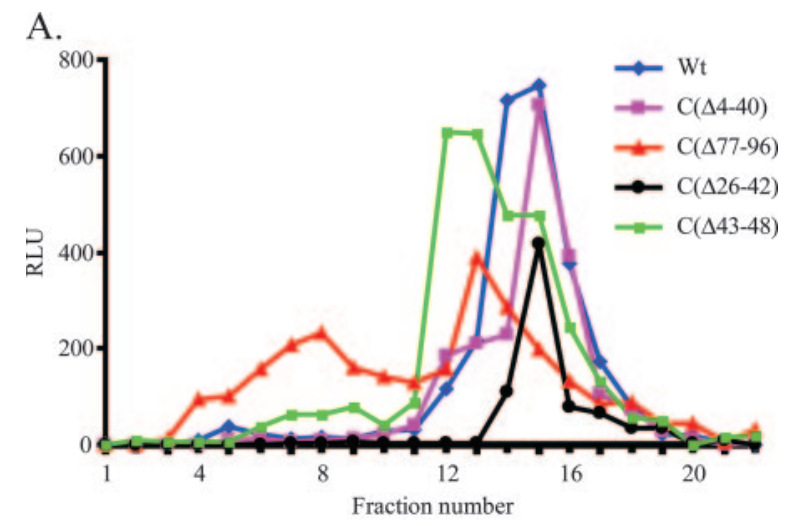

B.

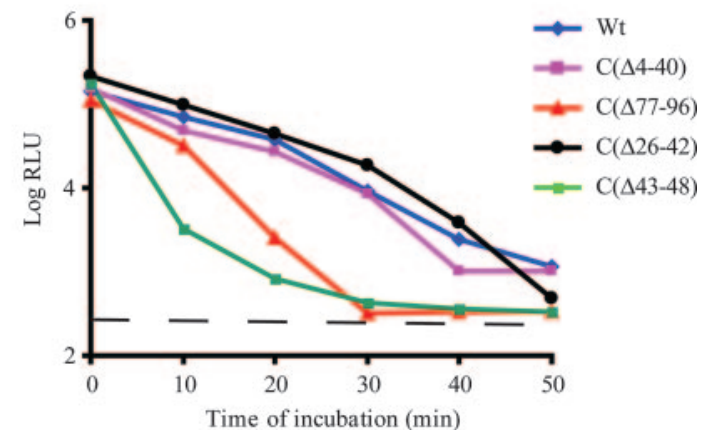

FIG. 5. (A) Velocity gradient sedimentation analysis of PIPs. PIPs were centrifuged on a continuous OptiPrep gradient. The gradient was fractionated, and BHK-15 cells were infected using $100 \mu \mathrm{l}$ of the fractions. Renilla luciferase activity in infected cells at 24 postinfection (on the $y$ axis) was plotted against the corresponding fraction number (on the $x$ axis). Renilla luciferase activity is expressed in RLU. PIPs generated using $C(\Delta 4-40)$ or $C(\Delta 26-42)$ sedimented similarly to wildtype (Wt) PIPs. (B) The thermal stability of the PIPs was assayed by incubating PIPs at $48^{\circ} \mathrm{C}$. Aliquots $(100 \mu \mathrm{l})$ were taken at 10, 20, 30, 40, and $50 \mathrm{~min}$ and used to infect BHK-15 cells. Renilla luciferase activity in infected cells at 24 postinfection (on the $y$ axis) was plotted against the time of incubation (on the $x$ axis). Renilla luciferase activity is expressed in RLU. The dashed line indicates background luciferase levels.

wild-type PIPs. Moreover, the profile of distribution for the $\mathrm{C}(\Delta 77-96)$ PIPs in the gradient revealed two peaks, suggesting two different species of particles. The profile was also much more varied for $C(\Delta 77-96)$ PIPs, in contrast to the sharp peak obtained for wild-type PIPs, suggesting that the $C(\Delta 77-96)$ PIPs were perhaps not as stable in the gradient.

Stability of PIPs. The stability of PIPs was analyzed by assaying their sensitivity to incubation at $48^{\circ} \mathrm{C}$ for 10 -min intervals up to $50 \mathrm{~min}$. In order to have an equal number of PIPs in the thermal stability assay, PIPs generated using different mutations of YFC were appropriately diluted to obtain similar luciferase activity in infected $\mathrm{BHK}$ cells, and those respective dilutions were used. As shown in Fig. 5B, the PIPs containing $\mathrm{N}$-terminal deletions $[\mathrm{C}(\Delta 4-40)$ and $\mathrm{C}(\Delta 26-42)]$ exhibited wild type-like thermal stability. However, the PIPs containing Cterminal deletions $[\mathrm{C}(\Delta 77-96)]$ or deletions within the IHS $[\mathrm{C}(\Delta 43-48)]$ were less stable than wild-type PIPS. $\mathrm{C}(\Delta 77-96)$ and $C(\Delta 43-48)$ PIPs were completely inactivated within $30 \mathrm{~min}$ of treatment at $48^{\circ} \mathrm{C}$ since no luciferase activity was detected in cells infected with these PIPs, while the wild-type and $C(\Delta 4-40)$ 
TABLE 1. Plaque phenotypes of viruses generated using mutated $\mathrm{C}$ protein

\begin{tabular}{lll}
\hline \multicolumn{1}{c}{ Type of mutation } & Mutation in YFC & Plaque size \\
\hline Internal deletion & $\Delta 26-36$ & Medium \\
& $\Delta 26-42$ & Small \\
& $\Delta 26-56$ & Lethal \\
C-terminal truncation & $\Delta 69-96$ & \\
& $\Delta 73-96$ & Lethal \\
& $\Delta 77-96$ & Small \\
& $\Delta 85-96$ & Small \\
& $\Delta 93-96$ & Small \\
& $\Delta 77-96 /$ Q45 & Medium \\
& & \\
Point mutation in helix 4 & L78N & Medium \\
& L81N & Small \\
& V88N & Medium \\
& M92N & Medium \\
& L95N & Medium \\
& L81N/V88N & Lethal \\
\hline
\end{tabular}

PIPs were stable even after $50 \mathrm{~min}$ of incubation at $48^{\circ} \mathrm{C}$. The thermal stability profile obtained for PIPs containing the L81N point mutation was similar to that obtained for the $C(\Delta 77-96)$ PIPs (data not shown). These observations suggest that the C-terminal $\alpha 4$ and the IHS, but not the $\mathrm{N}$ terminus, play a role in maintaining the stability of the PIPs.

Effect of capsid mutations on virus production. To study the effect of mutations in $\mathrm{C}$ protein on the viability of YFV, Cterminal truncations, internal deletions, and point mutations in the C-terminal helix were engineered into the full-length infectious cDNA clone of YFV. N-terminal truncations of the $\mathrm{C}$ protein could not be introduced due to the requirement of the $5^{\prime}$-cyclization sequence present in the coding sequence for amino acids 9 to 15 for genome replication. Mutations were introduced using standard PCR techniques, and these mutations are listed in Table 1. Full-length transcripts containing deletions were transfected into BHK-15 cells using DEAEdextran, and their plaque phenotypes were analyzed.

The results obtained in these mutational analyses of the $\mathrm{C}$ protein in virus compared favorably with those obtained using the trans-packaging system as described in the previous sections. As shown in Table 1, an internal deletion of residues 26 to 36 yielded an almost-wild-type-sized plaque phenotype while small plaques were obtained with a deletion of 26 to 42 residues. However, a larger deletion of 26 to 56 residues, encompassing $\alpha 1$ and $\alpha 2$ of DENC including the IHS, failed to produce any plaques. These results were similar to those obtained with analogous deletions in TBEC (18). Small plaques were obtained with smaller deletions within the IHS [C $(\Delta 43$ $48)$ and $C(\Delta 49-56)]$, but a deletion of almost the entire IHS $[\mathrm{C}(\Delta 43-56)]$, was not viable.

Small plaques were obtained upon transfection of RNA with a deletion of almost the entire C-terminal helix of the $\mathrm{C}$ protein $[C(\Delta 77-96)]$. Even larger $C$-terminal deletions, up to residue 73, were viable; however, no plaques were detected for a deletion of residues 69 to 96 . Again, these data are consistent with the results using the replicon and PIPs for assembly assays.

Point mutations in the C-terminal helix ( $\alpha 4$ in DENC) were introduced, and virus viability was assessed. The L78N, M92N,
V88N, and L95N mutations had moderate effects on virus viability, but the L81N substitution produced a virus with a small-plaque phenotype. No plaques were obtained with a double mutation of L81N and V88N, again reflecting the packaging result from PIPs in the replicon system.

To characterize the growth properties of mutants containing $\mathrm{C}$ protein deletions, cumulative growth curves were determined for some of these mutant YFV. Cells were transfected with either wild-type or mutated cDNAs, and virus released into culture supernatants was harvested at different time points posttransfection. The titer of infectious virus released was then calculated by a standard plaque assay. As shown in Fig. 6, there were significant defects in the release of mutant viruses as indicated by the reduction in the amounts of mutant viruses released from transfected cells compared to wild-type virus released at all time intervals. The overall titers of infectious virus released for the $C(\Delta 26-42)$ and $C(\Delta 89-96)$ reached only $10^{3} \mathrm{PFU} / \mathrm{ml}$, suggesting significant defects in virus release in these mutants.

With the purpose of obtaining additional spontaneous mutations that might restore virus viability, supernatants of BHK-15 cells transfected with RNA containing a deletion of the coding sequence for residues 77 to 96 of the $C$ protein were transferred onto fresh cells. Supernatants were harvested, and the production of viable virus and plaque phenotype were checked. Viable virus with a medium-size plaque phenotype was obtained. After having been subjected to multiple passages in BHK-15 cells, sequence analyses was done on this possible revertant, which confirmed the presence of the engineered $\Delta 77-96$ mutation but also revealed the presence of an additional mutation that resulted in substitution of a glutamine residue to a leucine $(\mathrm{Q} 45 \mathrm{~L})$ at position 45 in the $\mathrm{C}$ protein. To obtain direct evidence that this second site mutation was responsible for increasing viability of the $C(\Delta 77-96)$ mutant, the Q45L substitution was engineered into the cDNA of the infectious full-length virus containing the $\Delta 77-96$ mutation to obtain $\mathrm{C}(\Delta 77-96 / \mathrm{Q} 45 \mathrm{~L})$. Transfection of BHK-15 cells with $\mathrm{C}(\Delta 77-$ $96 /$ Q45L) in vitro-transcribed RNA resulted in plaques larger than those obtained with the $\mathrm{C}(\Delta 77-96)$ mutation alone, partially correcting the defect in the $\mathrm{C}(\Delta 77-96)$ mutant. We also engineered the Q45L mutation in $\mathrm{C}(\Delta 77-96)$ in the SIN-

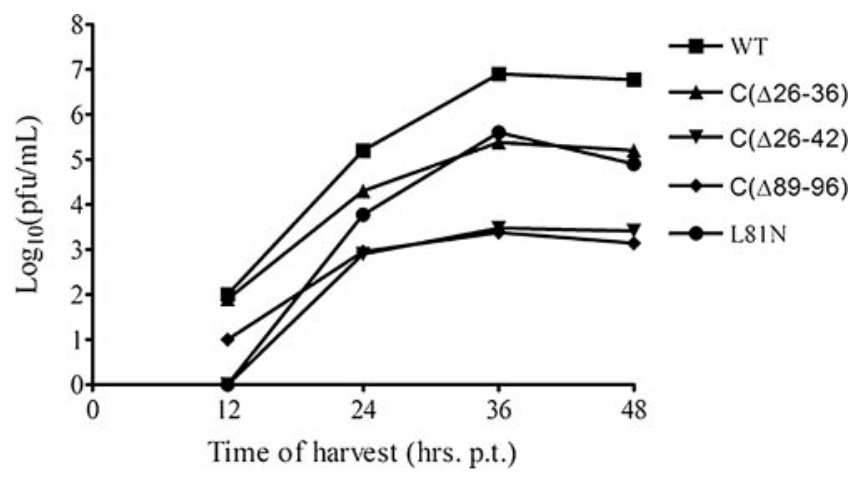

FIG. 6. Cumulative growth curves of wild-type (WT) and mutant YFV viruses. BHK cells were transfected with transcripts of cDNAs containing either wild-type or mutated $\mathrm{C}$ protein. Culture supernatants were harvested at 12, 24, 36, and $48 \mathrm{~h}$ posttransfection (p.t.), and titers of infectious virus released were calculated. 
CprME construct and checked for the resultant mutant's ability to package YF-R.luc2A-RP. Indeed, as shown in Fig. 4, the $\mathrm{C}(\Delta 77-96 / \mathrm{Q} 45 \mathrm{~L})$ construct had a higher packaging efficiency than the $C(\Delta 77-96)$ mutant alone. These results showed that the Q45L mutation alone was sufficient to increase the viability of the $C(\Delta 77-96)$ mutant.

\section{DISCUSSION}

Recent progress in the study of the molecular and structural biology of flaviviruses has led to a better understanding of the flavivirus life cycle, yet the mechanisms leading to genome packaging and virion assembly are still unknown. One of the first steps during assembly presumably involves association of the $\mathrm{C}$ protein and nascent viral RNA for formation of the nucleocapsid core. It was of interest to characterize the functional elements within the $\mathrm{C}$ protein important for genome packaging and virion assembly/disassembly. For this purpose, we utilized a YFV replicon-based trans-packaging system that involves using luciferase reporter gene activity as a measure of virus assembly in cells infected with particles formed using $\mathrm{C}$ proteins containing various deletions and point mutations. The assay of luciferase activity represents a sensitive method to obtain quantitative information on the efficiency of virus assembly. Similar to previous reports on TBEC, YFC was found to be remarkably flexible and could tolerate large deletions for the production of infectious virus particles. Analysis of some of these mutations in the $\mathrm{C}$ protein in the context of the virus was performed based on plaque phenotype, and the results were similar to those obtained using the trans-packaging system, thus substantiating the utility of the system for the study of $\mathrm{C}$ protein function in the absence of reversion and selection. One assumption in using this trans-packaging system to study virus assembly is that the luciferase activity determined for cells infected with PIPs is directly proportional to the amount of PIPs released from transfected cells and that this luciferase activity is not affected by problems in cell entry or disassembly. In order to show that the decrease in luciferase activity of PIPs was a direct result of the decrease in release of PIPs from transfected cells, wild-type or mutant PIPs were labeled with $\left[{ }^{35} \mathrm{~S}\right]$ methionine and partially purified by pelleting, and the resuspended pellets were analyzed by sodium dodecyl sulfatepolyacrylamide gel electrophoresis. A comparison of the intensities of $\mathrm{E}$ or $\mathrm{M}$ protein bands (a $\mathrm{C}$ protein band was not clearly visible for all the mutants tested) between wild-type and mutant PIPs revealed that a decrease in the amount of E protein (as determined by a decrease in the band intensity) was consistent with a corresponding decrease in the luciferase activity of PIPs, suggesting that the mutations within the $\mathrm{C}$ protein were affecting the assembly and release of infectious virus particles (data not shown).

The coding sequence for amino acids 9 to 15 of YFC contains a cyclization sequence that is involved in circularization of the genome and is essential for genome replication (7). It is difficult to elucidate the importance of the amino acids encoded by the cyclization sequence in the context of the virus since any change in the nucleotide sequence would preclude genome replication. In the trans-packaging assay, YFC is supplied using the SIN helper construct, and so the contribution of the amino acids of the $\mathrm{C}$ protein encoded by the cyclization sequence can be evaluated. We found that the deletion of the first 16 residues of the $\mathrm{C}$ protein had no effect on virus assembly, indicating that the amino acids encoded by the cyclization sequence are not involved in genome packaging or virus assembly.

The flavivirus $\mathrm{C}$ protein is highly basic, with positively charged residues distributed throughout the protein. In vitro binding experiments have shown that specific RNA binding is localized to the first 32 and last 26 residues of KUNC (15). Our results indicate that the first 40 or last 27 residues of YFC are dispensable for virus assembly, suggesting that residues at the $\mathrm{N}$ or $\mathrm{C}$ terminus perhaps compensate for RNA binding in the absence of the other basic terminus. An interesting feature of the $\mathrm{C}$ protein dimer is the nonuniform spatial charge distribution. The region with the highest density of positive charge is the solvent-accessible face of $\alpha 4$ (residues 74 to 96), and this region has been proposed to interact with viral RNA (26). Surprisingly, we found that $\mathrm{C}(21-76)$, containing 13 basic residues, was competent in virus assembly whereas $\mathrm{C}(37-88)$, containing 12 basic residues, was nonfunctional. It is unlikely that the presence of one more basic amino acid in $\mathrm{C}(21-76)$ than in $\mathrm{C}(37-88)$ is responsible for restoring virus assembly. A plausible explanation would be that the residues at the relatively flexible $\mathrm{N}$ terminus are in a more favorable conformation for RNA binding than the residues at the $\mathrm{C}$ terminus. Based on the different orientations of $\alpha 1$ observed in the structures of KUNC and DENC, it was suggested that $\alpha 1$ is flexible and perhaps plays a functional role in RNA binding (10). Taken together, these observations point toward a mechanism in which the $\mathrm{N}$ terminus of the $\mathrm{C}$ protein, encompassing $\alpha 1$, is involved in initial binding to the genomic RNA, followed by binding of the $\mathrm{C}$-terminal residues. However, in the absence of the $\mathrm{N}$ terminus, the $\mathrm{C}$-terminal residues can compensate for binding and packaging of the genomic RNA into the nucleocapsid core.

The flavivirus $\mathrm{C}$ protein is not free in the cytoplasm but is associated with ER membranes via the conserved IHS (29). In the DENC dimer, the $\alpha 2$ from each monomer forms an antiparallel helix that creates a large contiguous nonpolar patch. It has been proposed that this concave hydrophobic cleft formed by $\alpha 2-\alpha 2^{\prime}$ is responsible for membrane association (26). Kofler et al. demonstrated that viable TBEV particles with large internal deletions within the $\mathrm{C}$ protein were produced (18). The largest viable deletion corresponds to the removal of residues 28 to 49 in YFC. Larger deletions that extended to the $\mathrm{N}$ terminus of $\alpha 3$ failed to produce viable virus, but second site revertants to these lethal deletions restored viability. Many of these second site mutations involved single-amino-acid substitutions of a hydrophobic residue (19). It was proposed that the increase in hydrophobicity of the $\mathrm{C}$ protein containing the revertants enhanced the ability to interact with membranes and that this played a role in compensating for the defects of the deletions. Similar to TBEC, we found that YFC containing a deletion of residues 26 to 42 was viable but that a YFC with a larger deletion of 26 to 56 residues, encompassing $\alpha 1$ and $\alpha 2$, was dead. Interestingly, a deletion of the entire $\alpha 2$, which removed most of the IHS, was also viable, albeit with significant defects. These results imply that the IHS is not absolutely required for viability. In spite of several efforts, we were not 
able to recover second site revertants to return the viability of the $\mathrm{C}(\Delta 26-56)$ deletion mutant.

The flavivirus $\mathrm{C}$ protein is a dimer in solution, and it was of interest to find out whether the dimer was the functional unit of the $\mathrm{C}$ protein as well. As seen in the structure of the DENC and KUNC, two pairs of antiparallel helices, $\alpha 2-\alpha 2^{\prime}$ and $\alpha 4-$ $\alpha 4^{\prime}$, form the majority of the dimer contact surface. The $\alpha 2-\alpha 2^{\prime}$ interface is formed by the IHS from each monomer and is stabilized by extensive hydrophobic interactions. The long Cterminal helix, $\alpha 4$, contributes most significantly to support the $\mathrm{C}$ protein dimer and has the characteristics of a coiled coil (10, 26). We observed that viruses containing point mutations of residues L81 and V88, predicted to destabilize the $\alpha 4-\alpha 4^{\prime}$ dimer interface, have small defects in virus assembly but that a virus with a double mutation, $\mathrm{L} 81 \mathrm{~N}-\mathrm{V} 88 \mathrm{~N}$, is nonfunctional, suggesting that a stable $\mathrm{C}$ protein dimer is essential for assembly. Interestingly, as mentioned previously, viable YFV was obtained with a deletion of the entire $\alpha 4$. Similar observations made using an in vitro core assembly system have been reported in the case of the alphavirus $\mathrm{C}$ protein. Mutations in a predicted helix in the $\mathrm{N}$-terminal domain of the SIN capsid protein that destabilize the coiled-coil interactions with the corresponding helix in an adjacent $\mathrm{C}$ protein are more detrimental to core assembly than a deletion of the first 81 residues of the $\mathrm{C}$ protein that includes removal of the entire helix (33). In YFC, Q45L, the second site revertant to $C(\Delta 77-96)$, lies at the beginning of the IHS precisely at the $\mathrm{N}$ terminus of $\alpha 2$ and presumably stabilizes the weak (due to the deletion of $\alpha 4$ ) $\mathrm{C}(\Delta 77-96)$ dimer by increasing the hydrophobicity of the $\alpha 2$ $\alpha 2^{\prime}$ interface, thus correcting the assembly defect in $C(\Delta 77$ 96). Thermal stability assays of PIPs reveal that PIPs produced using $\mathrm{C}$ proteins containing either deletions within $\alpha 2[\mathrm{C}(\Delta 43$ $48)]$ or $\alpha 4[C(\Delta 77-96)]$ or mutations predicted to destabilize the dimer $(\mathrm{L} 81 \mathrm{~N})$ are less stable than wild-type PIPs, indicating that a stable $\mathrm{C}$ protein dimer is not only important for virus assembly but also perhaps plays a role in the stability of assembled virus particles. On the other hand, PIPs containing deletions in the $\mathrm{N}$-terminal region of the $\mathrm{C}$ protein $[\mathrm{C}(\Delta 4-40)$ or $\mathrm{C}(\Delta 26-42)]$ were as stable as wild-type PIPs. These observations highlight the importance of a dimeric $\mathrm{C}$ protein for virus assembly.

The flavivirus $\mathrm{C}$ protein belongs to the same class of alphahelical capsid proteins as the hepadnaviruses and retroviruses $(31,38)$. Similar structural motifs have also been observed in the core proteins of arteriviruses and bacteriophage $\Phi 6$ (9). Based on sequence analysis and biochemical studies the flavivirus $\mathrm{C}$ protein has also been compared to the $\mathrm{C}$ protein of alphaviruses (particularly that of the $\mathrm{N}$ terminus) and hepatitis $\mathrm{C}$ virus $(6,27)$. Many of these viruses have an established in vitro assembly system, which involves the use of either $E$. coli or cell extracts for expression of $\mathrm{C}$ protein and then association of the C protein with nucleic acid (RNA or DNA) for formation of CLPs $(5,24,36)$. Similar attempts at in vitro assembly of flavivirus CLPs by using E. coli-expressed DENC and YFC have proven unsuccessful so far (unpublished data). Based on our results, it is clear that the flavivirus $\mathrm{C}$ protein is remarkably tolerant of large deletions. The $\mathrm{C}$ protein is extremely flexible and demonstrates unusual relaxation of structural constraints for functional complementation by various regions of the $\mathrm{C}$ protein. In spite of this flexibility, two salient features of the $\mathrm{C}$ protein that are important for virus assembly are its ability to bind RNA and its ability to associate with membranes. Our results suggest that these associations occur through nonspecific interactions of basic residues with the viral RNA and hydrophobic residues with the membrane. The lack of an ordered nucleocapsid core as seen in the structure of DEN2 and WNV virions also suggests that RNA is packaged together in a nonspecific manner $(22,32)$. These results provide evidence for an assembly model in which core assembly, occurring in microenvironments, is initiated by the interaction of $\mathrm{C}$ protein with the viral RNA as well as with the ER membrane, and this provides the energy for higher-order oligomerization leading to virion assembly.

Although there does not seem to be any association between the inner nucleocapsid core and the outer glycoproteins embedded in the membrane as seen in the virion structure, it is likely that there is some interaction between the $\mathrm{C}$ and prM-E proteins during virion assembly. Recently, the involvement of nonstructural proteins, specifically NS2A and NS3, in virion assembly has also been implicated, although direct interactions with the $\mathrm{C}$ protein have not been demonstrated (23). Involvement of host cell proteins in flavivirus assembly has not been extensively documented but is thought to occur. Thus, we cannot rule out the possibility of disruption of motifs within the $\mathrm{C}$ protein involved in interactions with other viral or host proteins leading to assembly defects. The presence of at least two species of infectious particles in PIPs produced using $\mathrm{C}(\Delta 77$ 96) as observed in the velocity gradient centrifugation assay hints at the possibility of particles with more copies of $\mathrm{C}$ protein than in the wild type or the presence of multiple cores. A more comprehensive biochemical, analytical, and structural analysis of PIPs needs to be carried out.

\section{ACKNOWLEDGMENTS}

This work was supported by a Public Health Service Program project grant (AI45976) from the National Institute of Allergy and Infectious Disease. C.T.J. was supported by an NIH Biophysics training grant (GM08296).

\section{REFERENCES}

1. Allison, S. L., J. Schalich, K. Stiasny, C. W. Mandl, and F. X. Heinz. 2001 Mutational evidence for an internal fusion peptide in flavivirus envelope protein E. J. Virol. 75:4268-4275.

2. Allison, S. L., Y. J. Tao, G. O'Riordain, C. W. Mandl, S. C. Harrison, and F. X. Heinz. 2003. Two distinct size classes of immature and mature subviral particles from tick-borne encephalitis virus. J. Virol. 77:11357-11366.

3. Allison, S. L., K. Stadler, C. W. Mandl, C. Kunz, and F. X. Heinz. 1995. Synthesis and secretion of recombinant tick-borne encephalitis virus protein $\mathrm{E}$ in soluble and particulate form. J. Virol. 69:5816-5820.

4. Amberg, S. M., A. Nestorowicz, D. W. McCourt, and C. M. Rice. 1994 NS2B-3 proteinase-mediated processing in the yellow fever virus structural region: in vitro and in vivo studies. J. Virol. 68:3794-3802.

5. Birnbaum, F., and M. Nassal. 1990. Hepatitis B virus nucleocapsid assembly: primary structure requirements in the core protein. J. Virol. 64:3319-3330.

6. Choi, H. K., L. Tong, W. Minor, P. Dumas, U. Boege, M. G. Rossmann, and G. Wengler. 1991. Structure of Sindbis virus core protein reveals a chymotrypsin-like serine proteinase and the organization of the virion. Nature 354:37-43.

7. Corver, J., E. Lenches, K. Smith, R. A. Robison, T. Sando, E. G. Strauss, and J. H. Strauss. 2003. Fine mapping of a cis-acting sequence element in yellow fever virus RNA that is required for RNA replication and cyclization. J. Virol. 77:2265-2270.

8. Crill, W. D., and J. T. Roehrig. 2001. Monoclonal antibodies that bind to domain III of dengue virus E glycoprotein are the most efficient blockers of virus adsorption to Vero cells. J. Virol. 75:7769-7773.

9. Doan, D. N., and T. Dokland. 2003. Structure of the nucleocapsid protein of porcine reproductive and respiratory syndrome virus. Structure 11:14451451. 
10. Dokland, T., M. Walsh, J. M. Mackenzie, A. A. Khromykh, K. H. Ee, and S. Wang. 2004. West Nile virus core protein: tetramer structure and ribbon formation. Structure 12:1157-1163.

11. Ferlenghi, I., M. Clarke, T. Ruttan, S. L. Allison, J. Schalich, F. X. Heinz, S. C. Harrison, F. A. Rey, and S. D. Fuller. 2001. Molecular organization of a recombinant subviral particle from tick-borne encephalitis. Mol. Cell 7:593-602.

12. Hunt, A. R., C. B. Cropp, and G. J. Chang. 2001. A recombinant particulate antigen of Japanese encephalitis virus produced in stably-transformed cells is an effective noninfectious antigen and subunit immunogen. J. Virol. Methods 97:133-149.

13. Jones, C. T., L. Ma, J. W. Burgner, T. D. Groesch, C. B. Post, and R. J. Kuhn. 2003. Flavivirus capsid is a dimeric alpha-helical protein. J. Virol. 77:71437149.

14. Jones, C. T., C. G. Patkar, and R. J. Kuhn. 2005. Construction and applications of yellow fever virus replicons. Virology 331:247-259.

15. Khromykh, A. A., and E. G. Westaway. 1996. RNA binding properties of core protein of the flavivirus Kunjin. Arch. Virol. 141:685-699.

16. Khromykh, A. A., H. Meka, K. J. Guyatt, and E. G. Westaway. 2001. Essential role of cyclization sequences in flavivirus RNA replication. J. Virol. 75:6719-6728.

17. Kiermayr, S., R. M. Kofler, C. W. Mandl, P. Messner, and F. X. Heinz. 2004 Isolation of capsid protein dimers from the tick-borne encephalitis flavivirus and in vitro assembly of capsid-like particles. J. Virol. 78:8078-8084.

18. Kofler, R. M., F. X. Heinz, and C. W. Mandl. 2002. Capsid protein C of tick-borne encephalitis virus tolerates large internal deletions and is a favorable target for attenuation of virulence. J. Virol. 76:3534-3543.

19. Kofler, R. M., A. Leitner, G. O'Riordain, F. X. Heinz, and C. W. Mandl 2003. Spontaneous mutations restore the viability of tick-borne encephalitis virus mutants with large deletions in protein C. J. Virol. 77:443-451.

20. Konishi, E., and A. Fujii. 2002. Dengue type 2 virus subviral extracellular particles produced by a stably transfected mammalian cell line and their evaluation for a subunit vaccine. Vaccine 20:1058-1067.

21. Konishi, E., A. Fujii, and P. W. Mason. 2001. Generation and characterization of a mammalian cell line continuously expressing Japanese encephalitis virus subviral particles. J. Virol. 75:2204-2212.

22. Kuhn, R. J., W. Zhang, M. G. Rossmann, S. V. Pletnev, J. Corver, E Lenches, C. T. Jones, S. Mukhopadhyay, P. R. Chipman, E. G. Strauss, T. S Baker, and J. H. Strauss. 2002. Structure of dengue virus: implications for flavivirus organization, maturation, and fusion. Cell 108:717-725.

23. Kümmerer, B. M., and C. M. Rice. 2002. Mutations in the yellow fever virus nonstructural protein NS2A selectively block production of infectious particles. J. Virol. 76:4773-4784.

24. Kunkel, M., M. Lorinczi, R. Rijnbrand, S. M. Lemon, and S. J. Watowich 2001. Self-assembly of nucleocapsid-like particles from recombinant hepatitis C virus core protein. J. Virol. 75:2119-2129.

25. Lindenbach, B. D., and C. M. Rice. 2001. Flaviviridae, p. 991-1041. In D. M Knipe, P. M. Howley, D. E. Griffin, R. A. Lamb, M. A. Martin, B. Roizman, and S. E. Straus (ed.), Fields virology. Lippincott Williams \& Wilkins, Philadelphia, PA.

26. Ma, L., C. T. Jones, T. D. Groesch, R. J. Kuhn, and C. B. Post. 2004. Solution structure of dengue virus capsid protein reveals another fold. Proc. Natl Acad. Sci. USA 101:3414-3419.

27. Majeau, N., V. Gagne, A. Boivin, M. Bolduc, J. A. Majeau, D. Ouellet, and D. Leclerc. 2004. The N-terminal half of the core protein of hepatitis C virus is sufficient for nucleocapsid core formation. J. Gen. Virol. 85:971-981.

28. Mandl, C. W. 2004. Flavivirus immunization with capsid-deletion mutants: basics, benefits, and barriers. Viral Immunol. 17:461-472.

29. Markoff, L., B. Falgout, and A. Chang. 1997. A conserved internal hydrophobic domain mediates the stable membrane integration of the dengue virus capsid protein. Virology 233:105-117.

30. Modis, Y., S. Ogata, D. Clements, and S. C. Harrison. 2003. A ligand-binding pocket in the dengue virus envelope glycoprotein. Proc. Natl. Acad. Sci. USA 100:6986-6991.

31. Momany, C., L. C. Kovari, A. J. Prongay, W. Keller, R. K. Gitti, B. M. Lee, A. E. Gorbalenya, L. Tong, T. J. McClure, L. S. Ehrlich, M. F. Summers, C. Carter, and M. G. Rossmann. 1996. Crystal structure of dimeric HIV-1 capsid protein. Nat. Struct. Biol. 3:763-770.

32. Mukhopadhyay, S., B. S. Kim, P. R. Chipman, M. G. Rossmann, and R. J. Kuhn. 2003. Structure of West Nile virus. Science 303:248.

33. Perera, R., K. E. Owen, T. L. Tellinghuisen, A. E. Gorbalenya, and R. J. Kuhn. 2001. Alphavirus nucleocapsid protein contains a putative coiled coil alpha-helix important for core assembly. J. Virol. 75:1-10.

34. Pincus, S., P. W. Mason, E. Konishi, B. A. Fonseca, R. E. Shope, C. M. Rice, and E. Paoletti. 1992. Recombinant vaccinia virus producing the prM and $\mathrm{E}$ proteins of yellow fever virus protects mice from lethal yellow fever encephalitis. Virology 187:290-297.

35. Rey, F. A., F. X. Heinz, C. Mandl, C. Kunz, and S. C. Harrison. 1995. The envelope glycoprotein from tick-borne encephalitis virus at $2 \AA$ resolution. Nature 375:291-298

36. Tellinghuisen, T. L., A. E. Hamburger, B. R. Fisher, R. Ostendorp, and R. J. Kuhn. 1999. In vitro assembly of alphavirus cores by using nucleocapsid protein expressed in Escherichia coli. J. Virol. 73:5309-5319.

37. Wang, S. H., W. J. Syu, and S. T. Hu. 2004. Identification of the homotypic interaction domain of the core protein of dengue virus type 2. J. Gen. Virol. 85:2307-2314.

38. Wynne, S. A., R. A. Crowther, and A. G. Leslie. 1999. The crystal structure of the human hepatitis B virus capsid. Mol. Cell 3:771-780.

39. Yamshchikov, V. F., and R. W. Compans. 1993. Regulation of the late events in flavivirus protein processing and maturation. Virology 192:38-51.

40. Yamshchikov, V. F., and R. W. Compans. 1994. Processing of the intracellular form of the West Nile virus capsid protein by the viral NS2B-NS3 protease: an in vitro study. J. Virol. 68:5765-5771.

41. Zhang, W., P. R. Chipman, J. Corver, P. R. Johnson, Y. Zhang, S. Mukhopadhyay, T. S. Baker, J. H. Strauss, M. G. Rossmann, and R. J. Kuhn. 2003. Visualization of membrane protein domains by cryo-electron microscopy of dengue virus. Nat. Struct. Biol. 10:907-912.

42. Zhang, Y., J. Corver, P. R. Chipman, S. V. Pletnev, D. Sedlak, T. S. Baker, J. H. Strauss, R. J. Kuhn, and M. G. Rossmann. 2003. Structures of immature flavivirus particles. EMBO J. 22:2604-2613.

43. Zhang, Y., W. Zhang, S. Ogata, D. Clements, J. H. Strauss, T. S. Baker, R. J. Kuhn, and M. G. Rossmann. 2004. Conformational changes of the flavivirus E glycoprotein. Structure 12:1607-1618. 